\title{
Effect Analysis of Reinforced Concrete Beam with Opening Strengthened with Steel Sleeve
}

\author{
Shen Yaohui \\ Xiamen University Tan Kah Kee College, Fujian, Zhangzhou, PR of China, 363105 \\ yhshen@xujc.com
}

\begin{abstract}
Keywords: Reinforced concrete beam; Opening beam; The beam with opening strengthened with steel sleeve; Finite element analysis

Abstract: Based on finite element modeling of normal beam, beam with opening and beam with opening strengthened with steel sleeve, the author compares the changes of crack of the three kinds of beams in the loading process and its bearing capacity and deflection and combines with theories to analyze the mechanism of appearing of cracks, so as to find that commonly used reinforcement method of reinforcing concrete beam with steel casing has obvious deficiencies, in this sense, this paper provides ideas for improvement.
\end{abstract}

\section{Introduction}

In modern buildings, to meet the needs of installation of ventilation, air conditioning, hot water and water pipes, etc, opening hole in beams is always applied in operation. The opening of the beam has a great influence on the mechanical behavior of the beam. The main tensile stress and shear stress of the concrete surrounding the opening of the hole will increase greatly, and the stress concentration will appear at the entrance of the hole. The local stability of the concrete near the entrance of the hole will be decreased obviously ${ }^{[1]}$. Wang Xinling et al. ${ }^{[2]}$ perform experimental analysis of simply supported reinforced concrete deep beams with opening in the middle span under concentrated load to drop to the conclusion that bearing capacity of continuous deep beams with opening is related to the area and location of the opening, based on which restriction conditions and design suggestions are given. Liu Xiaochun et al. ${ }^{[3]}$ carried out experimental study on reinforced concrete simply supported short beams under concentrated load. It is found that the diagonal reinforcement can improve the transfer of force and has a significant inhibitory effect on the development of inclined cracks. Wang Peng et $\mathrm{al}^{[4]}$ study on the shear performance of the vertical hole opening of composite beams under static effect and draw the conclusion that the rigidity and bearing capacity of the composite beam are significantly reduced by the opening of the hole, and the bearing capacity and deformation capacity of the composite beam can be improved effectively by increasing the thickness of the concrete slab. At present, the common method of reinforcement is to place the steel casing at the entrance of the hole, and to reinforce the steel plate or the flange or the reinforcing rib outside the steel casing ${ }^{[1]}$, the reinforcement method is helpful for improving the bearing capacity of beam, but the degree is limited, and study on the beam deformation ability are not carried out. In this paper, the bearing capacity and deformation capacity of reinforced concrete beams strengthened with steel casing are studied and reinforcing effect of steel casing is investigated, to provide a new way for further research.

\section{Model Establishment}

Use the ANSYS finite element simulation software to simulate ${ }^{[5]}$ respectively the three beams, one of which is a normal beam without opening, one is beam with opening, another is beam with opening and steel sleeve reinforcement, which are simply supported structures. Width of beam is 200 ( $\mathrm{Z}$ direction), height of beam is 300 (Y direction), the total length is 3100 (X direction), net span is 2660, applied surface load within the range of 1000 1100 and 2100 2200 in the X direction, this paper uses stepwise loading method in the simulation process, the unit is load is proportional to the time (the time step multiplied by 20 is the total load, single $\mathrm{kN}$ ). The diameter of the opening of the 
opened beam is 80 , the center of the circle is located at 950 in $\mathrm{X}$ direction, 110 in Y direction. For beams with steel sleeve, the thickness of pile casing is 5. SOLID65 and link80 are used to simulate the concrete and steel bars, and the pile casing is simulated by solid95 unit element. The upper is allocated with $2 \Phi 8$ compression bars, the lower is allocated with $2 \Phi 18$ longitudinal tensile reinforcement, thickness of net protective layer of concret is $25 \mathrm{~mm}$ (counting from the edge of the longitudinal rebar), use 8@100 double hoop stirrup at the ends of hoops, 8@200 double hoop in middle zone, and C30 concert. The reinforced concrete model adopts the separated model, without considering the relative slip between steel and concrete. This paper adopts modified Newton-Raphson iteration method to solve the problem. The influence of different opening positions on the beam is different, this paper selects the most unfavorable position with larger shear force and bending moment to analyze the deformation response of steel casing reinforcement, as for opening reinforcement at other position, the mechanism is the same.

\section{Finite Element Analysis}

Crack of Normal Beam without Opening. The load deformation of the normal beam without opening is quite common, so there will not explained in detail. For the sake of the analysis, here only dose the crack diagram of the last calculation step is listed. Hereafter, the deformation is relatively large and the calculation is not convergent, so further data is failed to be obtained.

The crack diagram for the last sub-step of the normal beam without opening is shown in Figure 1, and the red part is the crack. In the simulation process, there firstly appear cracks in the mid-span in the No.17 sub-step, and the corresponding total load value is $5.41 \mathrm{kN}$. The maximum value that can be calculated is achieved in the No.30 mid-step, the crack diagram is as shown in Figure 1, the corresponding total load value is $9.825 \mathrm{kN}$. During the loading process of the beam, it is shown that it has good ductility, and has big deflection before destruction.

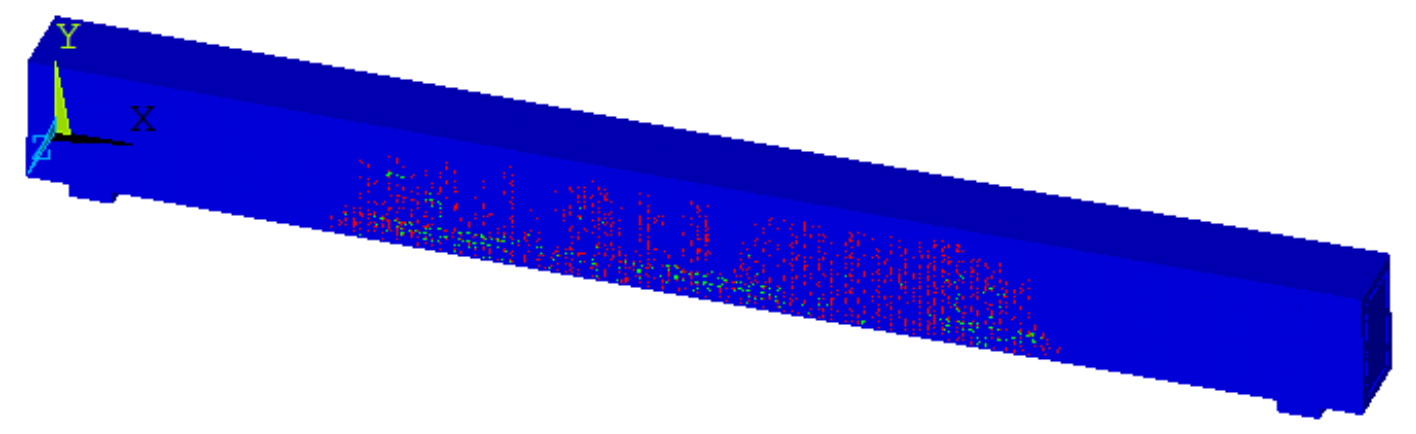

Fig. 1 Crack diagram of whole beam

Crack of Beam with Opening. The crack propagation condition of the beam with opening is as follow: in the No.9 sub-step, the crack appears at the remote support, and at this moment, the corresponding total load value is $2.51 \mathrm{kN}$, as shown in figure 2 . This condition is different from the normal beam. It is explained that there is no crack at the opening location, but there is a certain degree of deformation that leads to the warping of the remote support, so the crack appears. CRACKS AND CRUSHING
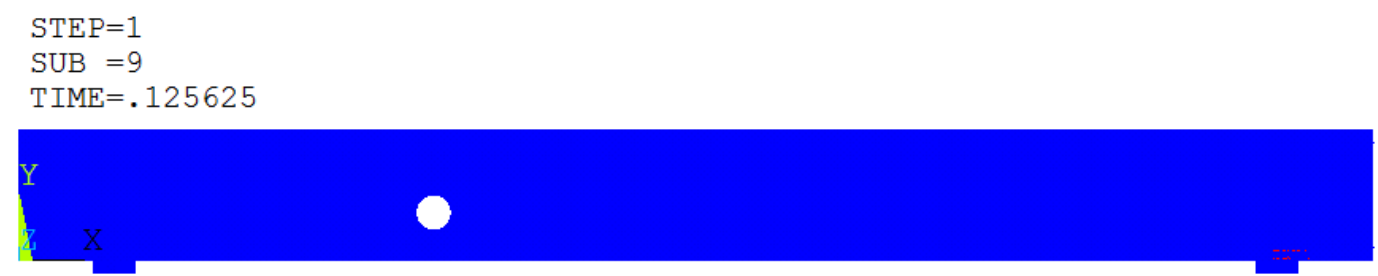

Fig. 2 No.9 sub-step crack diagram of beam with opening

In the process of gradual loading, the crack appears on the wall in the No.16 sub-step, and the crack extends to the surrounding of hole at the No.18 sub-step, moreover, the compressive zone of the upper part of the hole has been filled with cracks. As shown in Figure 3, at this moment, the corresponding total load value is $6.11 \mathrm{kN}$. 


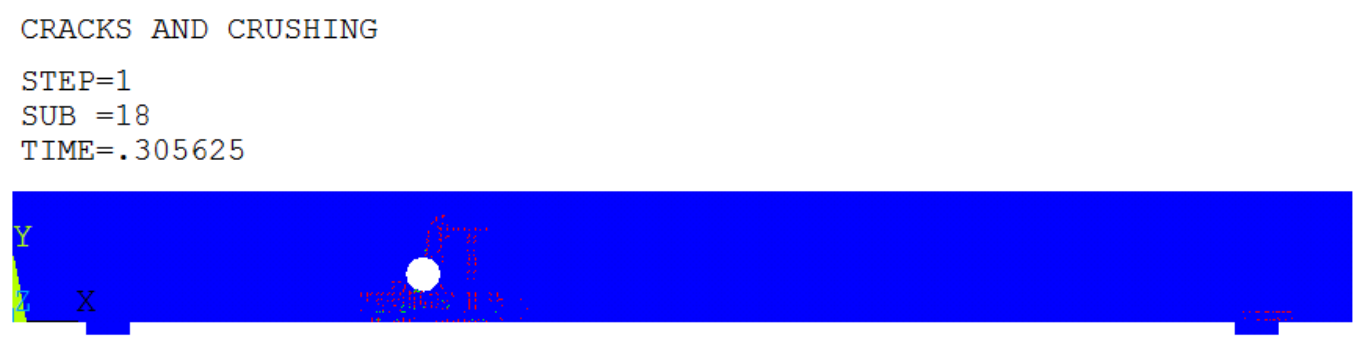

Fig. 3 No.18 sub-step crack diagram of beam with opening

In the No.19 sub-step, the beam is broken when the cracks appear in the bottom of the beam. At this time, the corresponding total load value is $6.51 \mathrm{KN}$. The results show that the ductility of the beam is very poor, showing the obviously brittle failure characteristics.

\section{CRACKS AND CRUSHING}

\section{$\mathrm{STEP}=1$}

SUB $=19$

$\mathrm{TIME}=.325625$

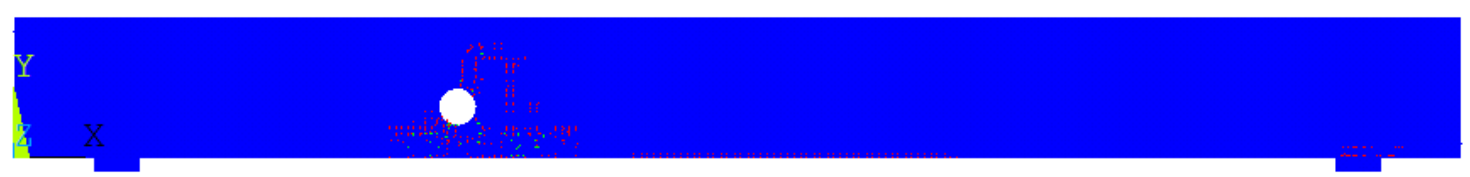

Fig. 4 No.19 sub-step crack diagram of beam with opening

Cracks of Beam with Opening Strengthened with Steel Sleeve. When the beam with opening is strengthened with steel sleeve, the crack firstly appears at the remote support in the No.9 sub-step, and at this moment, the corresponding total load value is $2.51 \mathrm{kN}$, which is similar to that of the strengthened beam with opening without sleeve. As shown in figure 5.
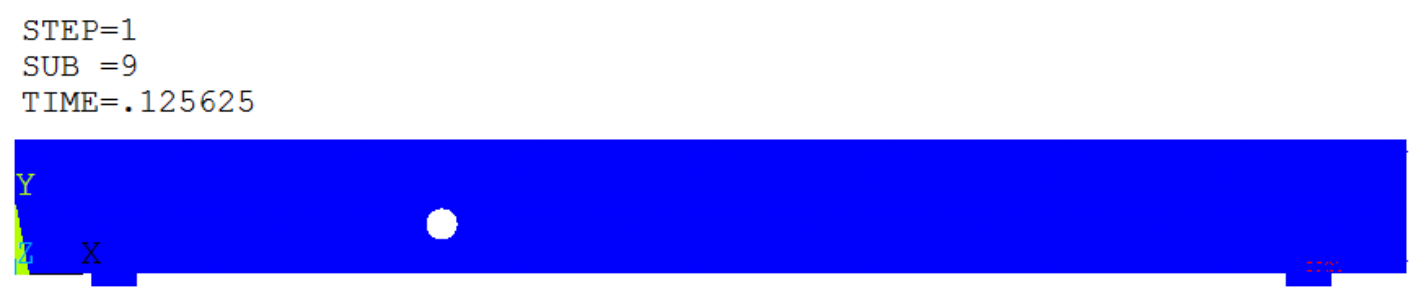

Fig. 5 No.19 sub-step crack diagram of beam with opening strengthened with steel sleeve

In the No.18 sub-step, the following cracks appear. Due to the role of the steel sleeve, the cracks do not appear on the wall of hole, but at the nearby location, and more cracks appear. After the inspection of its stress state, it is found that there is a large XY shear stress in this area, as shown in figure 7. The reason for this is because the stiffness of the steel sleeve is too large, and the deformation and concrete are not coordinated, causing that the too large concentrated stress appears at the surrounding concrete.

CRACKS AND CRUSHING

$\operatorname{STEP}=1$

SUB $=18$

TIME $=.305625$

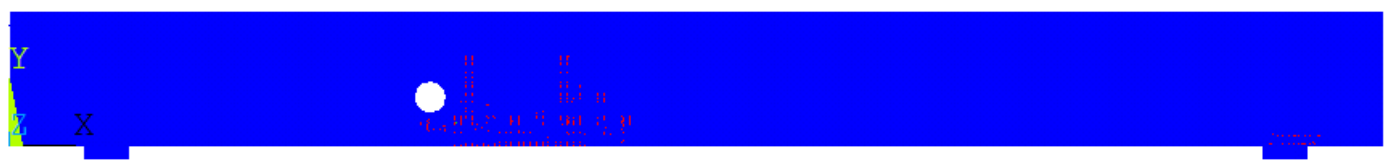

Fig.6 No.18 sub-step crack diagram of beam with opening strengthened with steel sleeve
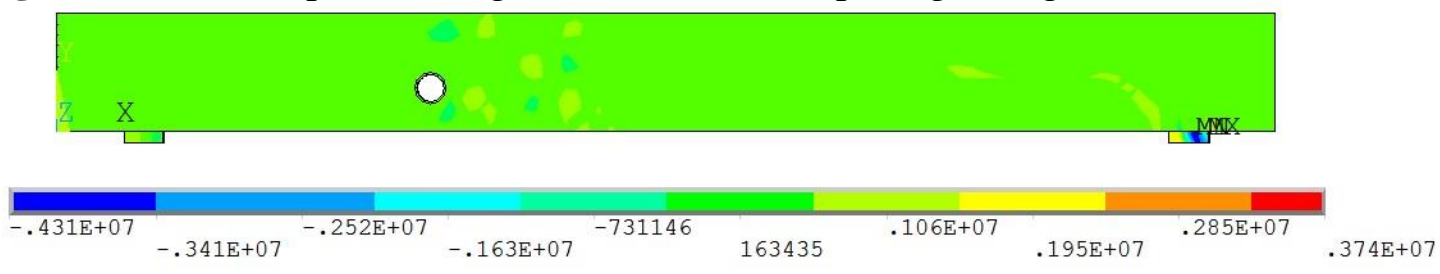

Fig.7 No.18 sub-step XY shear stress of beam with opening strengthened with steel sleeve 
In the No.19 sub-step, the cracks further increase around the hole, and the cracks also appear in the middle and lower edge of the beam span.
CRACKS AND CRUSHING
STEP $=1$
SUB $=19$
TIME $=.325625$

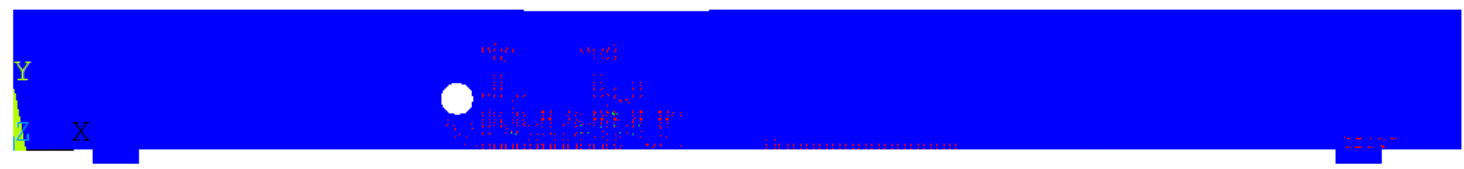

Fig.8 No.18 sub-step crack diagram of beam with opening strengthened with steel sleeve

In the No.21 sub-step, the beam reaches the maximum value of the bearing capacity, and then is largely deformed and damaged when re-loading. At this time, the crack propagation at one side near the mid-span of the hole is the highest, and the compressive zone is full of cracks. However, the mid-span crack only extends to the near area of neutral axis.

\section{CRACKS AND CRUSHING}

$\mathrm{STEP}=1$

SUB $=21$

TIME $=.365625$

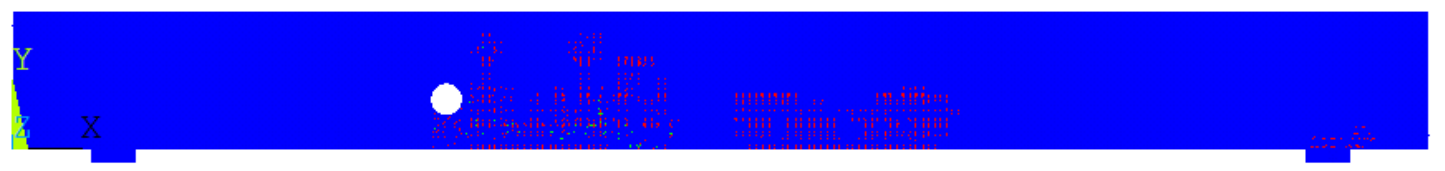

Fig.9 No.18 sub-step crack diagram of beam with opening strengthened with steel sleeve

The contrast of total load - deflection curves of the three beams is shown in Figure 10, from the figure, it can be seen that the bearing and deformation capacity of normal beam without opening are better, the bearing value reaches $9.825 \mathrm{kN}$, while the maximum deflection reaches $4.1 \mathrm{~mm}$. The bearing capacity of the beams with opening strengthened without the protective sleeves is only $6.51 \mathrm{kN}$, and the maximum deflection is only $0.63 \mathrm{~mm}$. The beam with opening strengthened with protective sleeves is slightly better than strengthened without steel sleeves, but the carrying value is only $7.31 \mathrm{kN}$, and the maximum deflection is only $1.08 \mathrm{~mm}$, it is explained that strengthening with the steel sleeve can improve the bearing and deformation capacity of the beam in some extent, but not ideal.

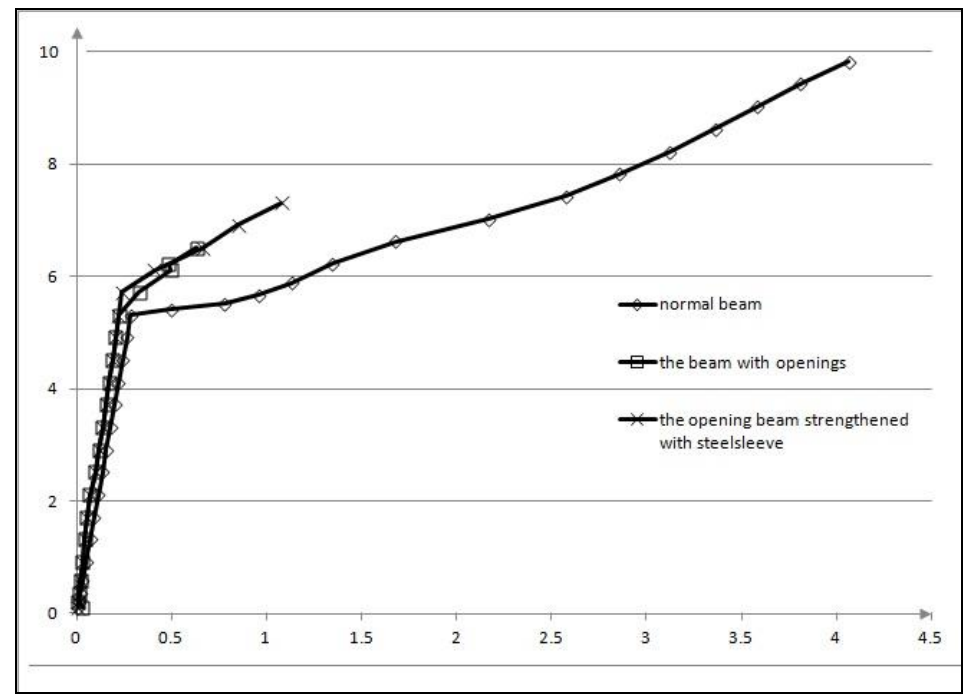

Fig. 10 Total load - deflection curves of beam

\section{Conclusion}

(1) In the loading process, the beams that open holes at harmful position firstly appear cracks on the wall of the hole, and extend to the surrounding area and the compression zone of the beam, and their the bearing and deformation capacity are much worse than the normal beams. 
(2) The bearing and deformation capacity of beams with openings strengthened with steel sleeve are better than that circule beams without strengthened, but the effect is limited. Because the stiffness of steel csleeve is much bigger than that of concrete, and both deformation are uncoordinated, causing that the surrounding concrete of steel sleeve appear concentrated stress, so the cracks appear, therefore, the stiffness of sleeve shall be reduced to coordinate the deformation of it and concrete, which can help to improve the overall deformation capacity of the beam.

\section{References}

[1] Ma Zhenyan, Wang Hongxin, Zhang Haisong, Zhang Zhenzhong. Study of Mechanical Property and Strengthening Methods of Reinforced Concrete Beam With Circular Hole [J]. Architectural Structure, 2013, 43( Z) : 545-548

[2] Wang Xinling, Gong Shaoxi. Anti-crack Calculation for Normal-section of Deep Beam with Mid-span Opening of Reinforced Concrete [J]. Academic Journal of Zhengzhou Engineering College, 1990, 11(3): 61-68

[3] Liu Xiaochun, Wang Mingping. Experimental Study of Short Beam with Simply Supported Opening of Reinforced Concrete [J]. Industrial Architecture, 2000, 30(5) : 32-35

[4] Wang Peng, Zhou Donghua, Wang Yonghui. Experimental Study on Shear Capacity of Steel Concrete Composite Beams with Web Opening [J]. Engineering Mechanics, 2013, 30( 3) : 297305

[5] Li Wei, Ye Yuming. Application Examples of ANSYS Civil Engineering[M]. Beijing: China Water Power Press, 2006 